\title{
TRANSLATION TEACHING AND COGNITIVE LINGUISTICS
}

\author{
BAAZIZ TERMINA \\ Mohammed V University of Rabat, Morocco \\ terminabaziz@gmail.com
}

\begin{abstract}
This paper is mainly concerned with the implications of cognitive linguistics for translation teaching and pedagogy. It sets out to succinctly chart some presumed shortcomings of replacement-based pedagogical methods that have long been centred around linear mechanical substitution of linguistic signs and patterns. Replacement approach, the paper argues, falls short of reinforcing what it takes to be the conceptual competence. In this connection, we account for our main assumption that translation teaching should be based on a sound theoretical footing that takes the conceptual system and the frames, or other structuring entities, populating it on board. Experimentally focusing on the conceptual system, cognitive linguistics' framework, we contend building on some relevant literature, provides a wide range of far reaching procedural models conductive to the innovation of translation pedagogy and practice. The examples investigated in the paper reveal that translation teaching may be more prolific if it is equally based on such models, which inform our understanding of textual lexico-semantic units in terms of their surface functioning as prompts serving for dynamically constructing semantic-conceptual equivalence.
\end{abstract}

Keywords: translation teaching, cognitive linguistics, conceptual system

\section{Introduction}

As the title implies, the present paper deals with translation teaching from the perspective of cognitive linguistics' framework. We will attempt to chart the contribution of this framework for opening up a new line of inquiry within translation pedagogy, which has long been centered around the strict mechanical replacement of signs. Apparently, while demonstrating their adequacy at the horizontal level, linguistic replacement-based methods of translation teaching fall short of providing the necessary conceptual skills that would enable translators to vertically reflect upon and conceptualize the structures indexed by symbolic units. When translating, meaning construction, in many cases, requires accessibility to the conceptual system. In this connection, we assume that translation students' problems are first and foremost conceptual in nature and not the other way round given that they supposedly master two or more linguistic systems. The point is that students are selected for admission to translation institutions based on the 
degree of their command of those systems, especially at the lexical and syntactic levels.

Drawing on the seminal cognitive models and approaches, predominating the cognitively-grounded literature, this research, which falls within 'applied translation' studies or 'applied extension' using Toury's (1995) terms, is an attempt to contribute to a maximalist perspective to Translation Teaching, beyond what traditional approaches to language semantics envision. Within cognitive perspective, language is taken in the context of cognition at large, where semantics and pragmatics are at play in tandem, i.e., a perspective that relates lexical knowledge to the world knowledge (Geeraerts 2009) organized in episodic memory. Following this perspective, the textual lexico-semantic units in texts are to be taken merely to serve as prompts for dynamically constructing semanticconceptual equivalence. It follows that translation teachers from cognitive linguistics' lens are invited to lend heavy importance to the conceptual network of students - as mediators - where situated meaning should be dynamically conceptualized and constructed.

The paper's lines of argumentation fall into three sections. At the outset, we will succinctly grapple with some translation teaching problems, which are associated, in the first place, with technical replacement, and then we will underscore some translation problems, which we take to be conceptual in nature. The second section lays out the main cognitive approaches to language, especially to semantics. The approaches on which this paper is primarily premised are those represented by the widely recognized models used as theoretical constructs for highlighting the multi-faceted organizational behavior of meaning as a conceptual phenomenon. Among the concerned models, which will be used in the paper interchangeably, we will sketch out frame semantics, idealized cognitive models, domains, image schema, in addition to simulation theory; Referring to some existing literature, these models relevant for translation teaching and pedagogy will be pointed out in the third section. Within the scope of this paper, the terms of frame, domain and ICMs, etc., are taken to refer to roughly the same structures (i.e., conceptual structures). The examples handled in this section show the extent to which such insightful approaches represent an adequate explanatory force for elucidating a handful of concepts central to translation teaching process, including equivalence (on which this paper focuses in the first place) and context.

\section{Translation Teaching and Translation Practice}

Irrespective of the daily several training hours spent in classrooms, translation institutions could not, relatively, provide the job market - marked by fierce competitiveness - with the sought number of highly competent and savvy graduates, who can manipulate their cognitive conceptual parameters, and who can provide top-notch products without lagging behind deadlines. This very fact, 
we assume, is to be attributed to translational pedagogy that falls short of building the conceptual competence of novice translators. We mean by conceptual competence the ability of activating the conceptual parameters involved in high order reasoning.

\subsection{Translation Teaching and Pedagogy}

Königs (1987) and Kiraly's (1995) remarks about what they conceive of to be the flaws of translation pedagogy, resulting from the persisting gap between theory and practice, apparently still relatively applies to today's translation classes, at least in the Arab world. This is the case notwithstanding the burgeoning body of research devoted to translation and translation teaching and pedagogy since the appearance of what is known as Holmes (1988) and Toury's (1995) maps that put forward new venues for translation research (e.g., see Risku 2000 for details about the development of cognitive orientation research for instance).

Kiraly (1995) levels a great measure of criticism against translation pedagogy because of depending substantially on practical orientation reduced to merely technical replacement at the linear level. Building on Königs (1987), Kiraly identifies the loci of the pedagogical gap in translation skill instruction; he pinpoints it in terms of lack of pedagogical objectives, curricular materials, teaching methods, and lack of systematic approaches. This latter notes that "Scholastic translation consists essentially of mechanical replacement of the linguistic signs $[\ldots]$ with allegedly equivalent signs from another language", with the aim of drilling or testing the student's knowledge of some aspects of foreign language such as comprehension, vocabulary, or grammar. Thus, in his viewpoint, classroom is turned into merely language-learning "with an emphasis on contrastive linguistics" (Kiraly 1995: 1-19). For the most part, students are trained on how to replace symbolic vehicles depending on linguistic or cultural taste of the target community or frequency of use, etc.

The replacement-dependent method of translation teaching is seemingly commonplace since it is collateral to the use of a host of linguistic and cultural models.

Teaching students how to translate resting heavily on structuralist approach that consists in syntagmatic signifiers replacement, i.e., text-and-dictionary based translational model of lexical or structural equivalence, is somewhat flawed; dictionaries are of limited support in building the translation necessary skills since they restrictively provide entries, their antonyms, synonyms, and semantic features of categories, etc (e.g., see Hejwowski 2004 for a detailed account on dictionary reliability). Transformative and generative model is also of limited utility. Such model is workable when it comes to reformulation of syntactic constructions. Likewise, truth conditions theory-influenced model, ontologically and rationally relating equivalent semantics of words to entities in the world, also proved its shortcomings in translation (cf. Kitis 2009: 71-73) and, thus, translation 
teaching; societies categorize the ontological world in different ways. Seemingly, the same applies to the models influenced by the "dominant notion of information processing as a rule-based manipulation of symbols which has proved to be highly problematic in recent years" (Risku 2000). The same holds true as well regarding the Critical Model, which places air-tight focus on cultural aspects of discourses, such as cultural values and ideas systems, including race, gender and power relations; such model is of limited utility in translation teaching (Kiraly 1995).

Given the shortcomings of depending heavily on such models, to mention but a few, translation teaching may improve if it draws on cognitive models on an equal footing with replacement strategies. Indeed, the cognitive approaches to/in translation represent the transition to a new paradigm conductive to the emphasis on the concept of the "situated translator, rather than the text, the ongoing and situated cognitive/ social work, rather than the contrasting relationships between pairs of language systems, culture or readerships" (Halverson 2014).

Mechanical replacement at the level of language system is by no means the whole story in translation and thus translation teaching. Translation, in many cases, is also a conceptual exercise that involves the activation of a number of cognitive structures (i.e., schemas, frames, domains, etc.) in the conceptual system as we will reveal later. That is to say, translation involves both linguistic and conceptual aspects. These two aspects in translation are evidenced, for instance, by Paradis' (1994) dual translation model, which has been elaborated by Christoffels and de Groot (2005). This model identifies two translation routes/ strategies at the disposal of translators; making use of either is conditioned by the extension of "the links already established between units in the two languages" (cf. Halverson 2014: 330-332). These are the 'horizontal' (referred to as 'transcoding') and 'vertical' strategies. The horizontal route implies that "source language input structures, be they words, common phrases, or idiomatic expressions, are directly replaced by the corresponding target language structures". In this case, the pathways are said to be entrenched (de Groot 2011: 320). By contrast, in vertical translation "access to the conceptual level is required" (Halverson 2014: 330-332).

In a nutshell, building on the lines of reasoning above, it is fair to emphasize that focusing translation teaching process on contrastive, linguistic replacement of signs is utile solely when it comes to horizontal strategy. By contrast, with regard to vertical translation, we view that translation teaching would be more prolific if it is equally oriented towards engineering the learner's conceptual system and, in connectionist terms, strengthening associations between its conceptual nodes to facilitate its accessibility, i.e., accessibility to frames and models inhabiting the said system.

\subsection{Translation Conceptual Problems}


This subsection is intended as an illumination of what seems to be some of the salient translational problems that translation pedagogy needs to draw attention to in light of cognitive linguistic models. Our starting point is that when graduating, a number of graduates bring with them certain observable conceptual problems, which surface in a number of chunks in some translated texts. Such problems should supposedly have already been solved in preparation classes.

\subsubsection{Factors that Influence the Search for Equivalence}

When undertaking translation projects, a number of novice translators may project what Shannon (1948) terms cognitive noise that presumably distorts the transmitted message. In many instances, they produce ambiguous, inaccurate or superfluous renderings throughout a number of lexico-semantic units of texts, and this sometimes affects the syntactic composition. It follows that some of the semantic properties and pragmatic forces of verbal acts reflecting some portions of information are lost; the point is that Gricean (1989) quantity maxim is flouted. The entropic behavior distributed in texts is, in essence, proportional to conceptualization problems, that is, cognitive problems, such as inaccessibility to accurate structuring frames and decision making based on simulation process, rather than language manipulation problems (Termina, 2018). Below, we shed light on some problems leading to such a sort of conceptualization pitfall, which should receive due attention in the teaching process:

\subsubsection{Technical problems}

Conceptual entropic behavior, we contend, is probably collateral to technical problems "derived from the conditions of source material, complexity of the content, topic area, word choice", etc., (Brislin 1970). We posit that such conditions and complexity bear upon word choice. More to the point, sometimes novice translators are cognitively uncertain about the degree of congruence between the frames indexed in the text and the probable choices represented in their mental lexicon or dictionary. Hence, we take the said technical issues to be conceptual more than anything else, for they presuppose the involvement of the conceptual system of the translator when it comes to vertical translation (cf. subsection 1.1). Technical problems of this sort might influence the search for equivalence.

\subsubsection{Cognitive asymmetry}

Another translational problem, which impacts equivalence, can be looked at from bilingualism perspective. The problem is associated with bilingual translational cognition, which might be characteristic of asymmetry in representation of categories as well as salience (Halverson 2014). Seemingly relating to vertical translation, such asymmetry would certainly affect the search for equivalence as well at the level of intra-categorical and inter-categorical units as well as the underlying frames. 


\subsubsection{Systemic factors}

The third conceptual problem relates to language and systemic factors, namely, to representation as constrained and shaped by the language network itself rather than the translator's cognition. Nida points out four problems of equivalence: (1) "the non-existence of a term in the receptor language but with an equivalent function being performed by another referent", (2) "the existence of the referent in the receptor language, but with a different function from what it has in the source language", (3) "the nonexistence of the referent in the receptor language and no other referent with a parallel function"; and (4) "necessity of syntactic transference of a message" (Nida, 1950/1975b: pp 44-45, cited by Kwon et al, 2009: 112). For instance, terms like courseware, paradigm, cognition, model, positivism, software, hardware, entropy, conceptualization, schemata, pattern, prototype, determinism, etc., fall within the first category. Apparently, terms of this sort do not have congruent referents in the Arabic language system; therefore, other referents are used to designate the concepts associated with them. By contrast, when the source text is Arabic, the employed referents might provide accessibility to inaccurate schemas, frames or cognitive models competing for activation:

Table 1. Examples of English terms without direct referents in Arabic language

\begin{tabular}{|c|c|c|c|}
\hline \multicolumn{2}{|c|}{ English into Arabic } & \multicolumn{2}{|c|}{ Arabic into English (possible candidates) } \\
\hline Courseware & بر امج حاسوبية & 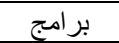 & Programs, courseware, software \\
\hline Paradigm & نموذج/أنموذج & 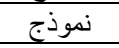 & Paradigm, model, example, etc. \\
\hline Pattern & i & نمط & Prototype, pattern, type, etc. \\
\hline Schemata & خطاطة & خطاطة & Chart, schema, schemata, etc. \\
\hline Schematize & خطط & خطط & Plan, schematize, draw, etc. \\
\hline Cognition & معرفة & 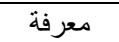 & Cognition, knowledge, etc. \\
\hline Determinism & حتمية & حتمية & Inevitability, determinism, etc. \\
\hline Prototype & نمط/نموذج & نموذج & Paradigm, model, example, etc. \\
\hline Entropy & اضطر اب & 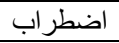 & Turbulence, entropy, etc. \\
\hline
\end{tabular}

Systemic factors influence what Nida terms semantic equivalence (cf. Kwon 2009,111 ) that turns out to be problematic, something which leads him to suggest dynamic or communicative equivalence. From cognitive linguistics vantage point, we hold that semantic equivalence may be taken in board to have conceptual implications as well, following the cognitive principle that "semantic structure is conceptual structure" (cf. section 2). The point is that lack of lexico-semantic structure within the linguistic network may induce a lack of conceptual structure and vice versa. It follows that a language that does not elaborate its terminology cannot provide access to some conceptual structures or frames, and this relatively applies to Arabic language in that it falls short of capturing scientific concepts. Likewise, there are referents in Arabic that do not exist in English, but these are 
not scientific terms. Consider for example the referential lexical unit that collocate with "qadia" (issue/cause/case) in (a): حيثيات القضية. Reasons or rationale are the referents used to express the meaning of حيثيات : With regard to the second category dealt with by Nida, the referent تمييع (liquidation or fluidization) in (c) has a different function in English:

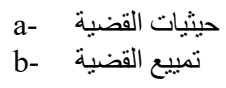

\subsubsection{Cosmopolitan vs. Local Frames}

There is a further problem having to do with the omnipresence of cosmopolitan frames in local contexts. This factor, by way of assumption, challenges the cultural approach to translation. It seems that cultural representations in the so-called the cosmopolitan era have been relatively synchronized into one representation resulting from intensification of human relations, technologization process, hybridity, informational holograms, multi-national organizations and suprainstitutions, global music and eateries, and so on (cf. Cronin 2006), and all these induce countless conceptual frames. Besides, human rights, democracy and consumerism frames are all active and interactive in local discourses. These major frames of sense making may influence many local ones. More to the point, a plethora of local referents gain their signification relative to a huge web of cosmopolitan conceptual relations. Therefore, it turns out to be difficult to talk about local conceptual frames with enough confidence. Apparently, translation, with regard to equivalence, must have been influenced by the cosmopolitan/centrifugal discursive processes. For this reason, we suggest that translation teachers should make students aware of such an issue, which is conceptual as well.

\subsubsection{Linguistic taste}

Notwithstanding the possibility of accessing the conceptual frames intended in the text, sometimes the translator might de-verbalize such frames and re-verbalize them into some given linguistic forms, which do not express the same frames, depending on the linguistic taste and frequency of use. That is, linguistic patterns are automatically chosen due to acceptability parameter in the receptor community. Taken as such, linguistic taste may influence equivalence choice.

\subsubsection{Some Possible solutions}

If one draws on the connectionist model known as 'Competition Model', as used in the context of second language acquisition (cf. MacWhinney1997), it is plausible to contend that translational cognitive asymmetry, technical problems, systemic factors, cosmopolitan frames and linguistic taste may all result in the activation of wrong candidate schemas and frames. For more clarification, when seeking equivalence, the loss of meanings may take place in the neuro-cognitive 
circuitry where wrong neural nodes and paths, which substrate wrong conceptual frames or cognitive schemas, compete for winning reenactment in simulation process (for more details on simulation see section 2).

Generally speaking, for solving conceptual problems, particularly asymmetry and technical problems, it is incumbent upon teachers to motivate their students to rigorously engage in supervised and non-supervised extensive reading in both languages (SL and TL). I mean by supervised reading showing them how to glean the webs of bottom-up and top-down frames. Apparently, extensive reading reduces the scope of representational asymmetry and complexity, etc. According to our understanding, connectionism (cf. McClelland 2013a for details on connectionism) proposes ways of handling such problems; they might be solved, for instance, via engaging students' bilingual conceptual networks (L1 and L2) in frequent connections that, at the substrate neural level, recruit old and new neurocognitive assemblies. Exercise and repetition of patterns of activation alongside with connections adjustments expand translation students' conceptual neurocognitive networking. The idea of frequency and exposure is also tackled in the vast body of literature on the impact of usage on cognition (cf. for example Ellis 2008; Bybee 2003; 2004, among others). For instance, Bybee (2003) clearly pinpoints that processing across speech events enables items to have memory representations.

With regard to reference problems of the sort handled above, these might neither be solved by linguistic replacement, nor by usage and frequency at a long term level. Instead, they in a sense require the involvement of terminologists and lexicographers. In the approach taken in this paper, the problem of reference and correspondence is relatively amenable to theoretical treatment and feasible to deal with in classroom from a conceptual cognitive lens, more specifically from cognitive linguistics perspective. For example, teachers may, we suggest, train their students' conceptual system, at least, on how to straightforwardly detect the types of the aforementioned reference-related systemic factors, and equally on how to conceptualize the constituting attributes and values of SL and TL frames indexed by referents at variance.

Concerning cosmopolitan and local frames competition for activation, one may stipulate that translation students can solve such problems when they are taught the importance of context in rendering conceptual frames. Choosing either is dependent on their institutional agency or emotional community targeted by the translation, etc.

To conclude this subsection, connectionist approach provides ways of understanding activation and connections strengthening, and thus, it is consistent with cognitive linguistics' line of enquiry. Avoidance of the wrong frames activation requires access to the intended ones. However, access cannot occur unless a translator has such intended frames as input in the conceptual system. It follows that translators should learn how to make use of their conceptual systemthat is to be accessed by lexical items- for handling a number of cognitive and 
conceptual issues. In the coming section, we will pinpoint a handful of models that investigate the structures that inhabit the conceptual system, including frames, schemas, domains, cognitive models and simulators relative to which linguistic items and linguistic knowledge are to be understood.

\section{Cognitive Linguistics' Framework}

Having pointed out, in the foregoing, some of what seems to be translation and translation teaching problems, the ultimate aim of this section is to succinctly lay out cognitive linguistics framework, which appears to be pedagogically useful in reinforcing translation students' conceptual competence. Cognitive linguistics puts at the disposal of translation teachers a wide variety of practical tools which are of vital utility for targeting students' conceptual systems - as mediators, where meaning is dynamically conceptualized and constructed. This field can be invested in to show students how to come to grips with a number of conceptual problems (or, at least, to make them aware of those entailing the involvement of terminologists and lexicographers).

\subsection{Tenets and Assumptions}

Following Evans (e.g., 2007; 2009), cognitive linguistics is concerned with investigating the relationship held between experience, the conceptual system, and the semantic structure encoded by language (cognitive semantics) and language system-i.e., mental grammar - (Cognitive approach to grammar). Cognitive linguistics is oriented by two major commitments and roughly four guiding principles (Evans 2007: 6). A number of assumptions, which constitute the encyclopedic approach to meaning, derive from such principles (Evans 2007: 11):

\section{Commitments:}

1- Generalization commitment (generalizing what is known about the mind to language).

2 - Cognitive commitment (language is related to other cognitive abilities).

Principles:

1- Conceptual structure is embodied (the 'embodied cognition thesis');

2- Semantic structure is conceptual structure;

3- Meaning representation is encyclopedic;

4- Meaning construction is conceptualization.

Assumptions:

1- There is no principled distinction between semantics and pragmatics;

2- Encyclopedic knowledge is structured;

3- Encyclopedic meaning emerges in context; 
4- Lexical items are points of access to encyclopedic knowledge.

5- Encyclopedic knowledge is dynamic.

Cognitive linguistics draws a sharp distinction between language system and conceptual system, albeit they are inextricably interconnected. Cognitive semanticists argue that the conventional meaning associated with a particular linguistic form is simply a 'prompt', or, if you will, an access point for reaching the conceptual system where conceptualization occurs; conceptualization involves the 'selection' of an appropriate interpretation against the context of the utterance. Contextual clues constrain the part of the encyclopedic knowledge to be activated. To put it another way, meaning construction operates at the level of conceptual system, where access to encyclopedic knowledge takes place (cf. Evans 2007; 2009). To illustrate this point, Evans (2007: 8-9) gives the following example of 'safe' in the context of a child playing on the beach as discussed by Fauconnier and Turner (2002):

\section{Sentences}

a. The child is safe

b. The beach is safe

c. The shovel is safe

\section{Meaning as constrained by context}

The child will not come to any harm

The beach is an environment in which the risk of the child coming to harm is minimized

The shovel will not cause harm to the child

Indeed, a range of approaches have been developed within cognitive linguistics with the aim of modelling word knowledge and world knowledge continuum in compliance with the two commitments and, thus, substantiating the abovementioned principles and assumptions.

\subsection{Cognitive-Linguistic Approaches}

The cluster of approaches elaborated under the heading of cognitive linguistics is quite large. However, this paper highlights just the most influential ones, namely, those associated with certain theoretical constructs such as frame, idealized cognitive model (ICM), and domain, ${ }^{1}$ in addition to simulation model. Each construct "provides a way of characterizing the structured encyclopedic knowledge" (Cienki 2010: 171). These notions within the scope of the paper at hand are, to some extent, used interchangeably to refer to such "relatively stable background knowledge structures with respect to which lexical concepts are relativized", that is to say, the structures supposedly inhabiting the conceptual system and organizing information in memory. Nonetheless, it seems of vital importance to refer to the characterization of the said structures from the

1 Frames, ICMs, and domains are notions deriving from the approach to language as a system of communication. Such a system reflects the world as it is construed by humans (cf. Cienki 2010: 171). 
perspective of each theoretical model that uses its own terms in referring to them. The multiple ways of characterization are essential in terms of offering a rich range of concepts that may be exploited in various ways in translation teaching at the level of theory and practice in the Arab world (at least), where research on cognition at large is still in its infancy. In the West, cognitive models have already been brought to the forefront in translation studies.

\subsubsection{Frame Semantics and Idealized Cognitive Model}

The notion of frame, which has received the bulk of attention in translation studies to date, has been framed in multiple ways. It has been addressed by Fillmore, Lakoff, and Barsalou, among others. In general terms, we will use the concept of frame later to refer to the other constructs (domain, image schema and ICM).

According to Geeraerts (2009: 198-199), Fillmore (e.g., 1977; 1985;) "uses the notion of 'frame' both in a broader sense and in a more restricted sense". It is used in the broadest sense as "largely synonymous with that of Idealized Cognitive Model, referring in general to the knowledge structures that embody our thinking about the world"; in this sense of the term, a frame may involve elements like imaginings, beliefs, and expectations one has about the world. In turn, in his account for the underlying conceptual structures of political debate in the US, Lakoff (e.g., 1996) refers to the concept of framing as tantamount to the way Idealized Cognitive Models ${ }^{2}$ (and more specifically metaphorical models) are employed to redirect public debate on particular social and political issues (Geeraerts 2009: 198-199). In the restricted sense, frame semantics, which grew out of Fillmore' s (1977) fine grained analysis of case grammar, is used to underscore "a specific type of knowledge organization in the lexicon" ${ }^{3}$. Such knowledge is relational in that when a conceptual element is activated, it follows then that all the other elements within the frame would receive activation (i.e., spread of activation in connectionist terms). For example, in the commercial transaction frame, when the concept of buying is activated, activation spreads to encompass seller, buyer, goods, and money, etc. Besides, a set of verbs, nouns, prepositions, etc., might be activated all at once.

In addition to the contrast between frame and ICM, frame can further be understood in association with other related terms, including script/scenario taking place within the frame. Differences between the terms are explained (Coulson \& Teenie 2009), for example, as follows:

The term frame is used to characterize background knowledge about objects, and includes slots which may be filled either through a slot-filling process or with default values. Default values consist generally of the most typical and/or the most frequent filler for each slot and

2 Lakoff's account on cognitive models "was less concerned with developing an approach to encyclopedic semantics than with addressing issues in categorization" (cf. Evans 2007: 12).

3 Frame semantics theory is interested, in particular, in revealing how language is employed to "perspectivize an underlying conceptualization of the world". when we use language, conceptual models might be verbalized by users in various ways (cf. Geeraerts 2009: 200). 
are invoked in the absence of other information. Scripts represent stereotyped sequences of events such as going to a restaurant, and contain slots that are either filled by binding the particular fillers manifest in the situation at hand, or by instantiating the default value for any particular slot. (Coulson and Teenie, in Sandra et al 2009).

The description above is pertinent in terms of distinguishing between frame and scenario/script taking place within the frame. However, it looks at frame as a fixed entity with slots. The idea of fixedness might be traced back to artificial intelligence-based line of inquiry associated with Minsky (1977) and other scholars (cf. Barsalou 1992). Building on the notion of frame in artificial intelligence and frame semantics, etc., Barsalou (ibid) provides a further identification of frame in the field of cognitive psychology.

Barsalou (ibid) makes it clear-cut that frames are structures that "represent all types of categories, including categories for animals, objects, locations, physical events, mental events", and so on. This latter holds that even representation of word classes, including objectives, adverbs, and quantifiers, etc., is also feasible in his conception of frame (ibid: 29). A frame may comprise several frames, and each frame is composed of four interrelated components: attributes (shapes, color, locations, paths, etc.), values (subordinate concepts of attributes), structural invariants and constraints (ibid: 21). Barsalou points out that people can constantly construct attributes depending on context of use and their goals by virtue of the fact that frames are dynamic relational structures ${ }^{4}$. Attributes in a frame are not to be conceived of as independent slots but are somewhat related correlationally and conceptually ${ }^{5}$. Structural invariants capture a wide variety of concept relations. Regarding constraints, Barsalou (ibid) identifies four types thereof: attribute constraints, value constraints, contextual constrains, and optimization constraints (ibid, 37), which they constrain relations within a frame. In transportation frame, the attribute Speed whose value is slow, for instance, constrains the attribute cost whose value is low, and speed constrains duration, and so on.

Building on the literature about frame notion, Manuel de Vega (1984), according to Rojo López (2002: 316), provides a frame typology. This latter outlines five types of frames: 'visual frames', 'situational frames or scripts,' 'domain frames', 'social frame's and 'self-concept frames.'

To sum up, there are different framings of the notion of frame; however, all the framings are important in the characterization of the concept, and it follows that they offer a variety of procedural concepts for contributing to the innovation of translation pedagogy.

4 Barsalou (1992: 35) refers to this property as attribute systematicity.

5 Barsalou (1992) holds that correlational relations develop between them, somewhat like those in connectionist nets. 


\subsubsection{ICMs and Image Schemas}

Like frame notion, the construct of Idealized Cognitive Models (ICMs) also relates to further terms, including mainly image schemas suggested by Lakoff (1987), Lakoff and Turner (1989) and Johnson (1987). The term image schema refers to "a recurring, dynamic pattern of our perceptual interactions and motor programs that gives coherence and structure to our experience" (Cienki 2010: 179). Lakoff's account of idealized cognitive models implies that some models may involve image schemas, which function as major structuring elements. Each schema "represents a simplified (idealized) abstraction of some pattern in our bodily experience which we use as a model for conceptualizing other (more abstract) aspects of our lives" (Clausner and Croft 1999: 4). This sort of cognitive models may, supposedly, employ the mechanism of metaphorical mapping to link schemas to their relevant target domains (Cienki 2010: 180).

\subsubsection{The Notion of Domain}

Domain constitutes another theoretical construct in cognitive linguistic investigation into language as a conceptual subject matter. Apparently, the term has developed independently in two main contexts, namely, the context of conceptual metaphor theory and that of Cognitive Grammar (Cienki 2010: 180). The notion of domain is of significant importance in informing our understanding about how translation might be taught from the conceptual perspective, especially in terms of teaching part whole relations and detection of conceptual mappings.

In his line of inquiry about conceptual metaphor, Lakoff (1993) deals with the term domain to explain inter-domain mappings. A conceptual metaphor is the production of mapping between two "domains of experience"; source domain properties are conceptually projected onto source domain. Thus, target domains of experience are schematically understood with reference to source domains. In addition to the notion of domain, image schemas are also said to be involved in conceptual metaphor. Clausner and Croft (1999: 4) propose that image schemas are subtype of domains", which they call image schematic domains. Image schemas represent "schematic patterns arising from imagistic domains, such as containers, paths, links, forces, and balance that recur in a variety of embodied domains and structure our bodily experience". These cognitive primitives extend to capture non-bodily experiences by means of conceptual metaphor (Lakoff 1987: 453; Johnson 1987: 29; see Clausner and Croft 1999: 14).

In his Cognitive Grammar, Langacker (1987: 488) defines "domain" as "a coherent area of conceptualization relative to which semantic units may be characterized." The term covers a number of cognitive entities types, including, for instance, mental experiences, representational spaces, concepts, and conceptual complexes, etc., (Cienki: ibid). On the one hand, domains fall into two categories: "Basic domain" that cannot be reduced into smaller entities and "abstract domain" which constitutes "any concept or conceptual complex that functions as a domain for the definition of a higher-order concept" (Langacker 
1987: 150). For example, in order to understand what an elbow (basic domain) knowledge about the (abstract) domain of 'arm' is required. On the other hand, a domain is composed of profile indexed by a lexical item and base (such as the arc and circle). The set of domains accessed in a communicative situation is termed 'domain matrix'. Cienki (ibid) notices that Langacker (1987:150) considers an abstract domain to be an equivalent to an ICM, a frame, scene, schema, or possibly a script (Taylor 2001: 439; Langacker 2008: 47, for further details see Cienki 2010).

If the conception on frame can help us in taking account of the activation of individual frames or structures building on individual items indexing them, domains theory is insightful in terms of accounting for domain matrices, i.e., for the distribution of information in the textual domains to be accessed by lexical profiles.

\subsubsection{Situated Simulation Theory}

A further cognitive and conceptual mechanism that can far refine our understanding of translation teaching process is that of perceptual and conceptual simulation model suggested by Barsalou in his Symoblic Systems Theory (e.g., 2003b). Simulation-oriented account has a lot to offer to translation teaching, particularly in terms of improving students' simulation activity and its situatedness.

Barsalou defines simulation as follows: "simulation is the reenactment of perceptual, motor, and introspective states acquired during experience with the world, body, and mind" (ibid). Barsalou notes that language operates, first and foremost, at the level of frame parameters; the process of understanding involves imaginative simulation invoked by the activated frames (cf. Feldman 2006: 147). It has been suggested that there are common characteristics shared by conceptual and perceptual representations. For example, Barsalou (ibid) suggests that "schematic representations of perceptual experience are stored around a common frame that promotes schematized simulations, which recruit neural machinery activated in perceptual experience from all modalities" (cited by Coulson \& Teenie, in Sandra et al 2009: 101).

Drawing on this theoretical line, simulation is inextricably linked to frames inhabiting the conceptual system in which simulation takes place building on perceptual symbols (cf. Evans 2009). Taken in this sense, perceptual symbols used in simulation "help explain the intentionality of our concepts $[\ldots]$ by grounding concepts in perceptual experience" (Coulson \& Teenie, in Sandra et al, 2009: 101). The meanings and conceptions triggered off by utterances serve as facilitators of diffusely activated simulations (Zwaan 2004). Thus, the role of linguistic items is to re-activate neural activation patterns, labelled at the functional level simulators (similar role of ICMs in Lakoff 1987, mental models in Johnson-Laird1983 and frames in Fillmore 1985). 
These notions are criticized because, for instance, "it is not necessarily clear how to demarcate what is or is not part of a given frame, ICM, or domain" (Cienki 2010: 184). Thus, domain concept is used in the literature interchangeably with Fillmore's frame and Lakoff's ICM (e.g., see Temmerman 2000; Faber 2009). The same holds true for the other constructs. However, apart from the accounts on whether such constructs are interchangeable conceptual structures or not, each theory offers a bunch of different insights which complete each other for a detailed understanding of cognitive linguistics functioning.

To conclude this section, having presented the various characterizations of cognitive and conceptual structures accessed in the conceptual system through activating linguistic units, we arrive at the following points, which are not conclusive. First, knowledge structures can be understood in terms of parts and wholes (basic domains and non-basic domains, or generic frames and sub-frames). Second, conceptual metaphor extends bodily and non-bodily domains into other domains of experience through image schemas generalization. Third, Idealized Cognitive Models, which employ image schemas and contain domains, are the cognitive versions we have about reality. Fourth, frames are dynamic structures which may contain scripts and scenarios; they have values and attributes which constrain each other within webs of relations. Finally, simulation makes use of frames playing the role of simulators, and it is a prerequisite process for choosing the accurate frames since it enables us to act upon them in our imagination. However, recall that these conceptual devices may be used to refer to each other since they are used in the literature on translation as such. In most of the part the term frame is used to refer to the other theoretical notions.

\section{Relevance of Cognitive Linguistics in Translation Teaching}

In the previous section, we have sketched out the prominent cognitive linguistics models constituting cognitive linguistics' framework. In this section, we intend to briefly touch upon the relevance of the framework' seemingly appealing findings and their application in pure translation studies, and thus translation teaching as an applied translation purview. The aim is to demonstrate the extent to which cognitive semantics can contribute to accounting for the gap in translation pedagogy (cf. subsection 1.1), which has long been centered around mechanical replacement in the first place. Cognitive linguistics conception is of vital relevance for translation teaching due to the due attention drawn to both language system and conceptual system, albeit the pinpointed theoretical constructs within this field are used in translation to refer to almost the same thing (knowledge structures). 


\subsection{Cognitive linguistics framework in translation study}

\subsubsection{General Translation}

The field of cognitive linguistics demonstrates its adequacy in explaining the translation process. As a point of fact, plethora of works have contributed to translation studies within the framework of cognitive linguistics; however, in what follows, we succinctly discuss few examples. The results arrived at in each work are useful for informing our understanding of translation pedagogy, in terms of both theory and practice.

Adequacy of cognitive linguistics is well-evidenced, for example, in Vannerem and Snell-Hornby's (1986) seminal and influential work, in which Fillmore's (1977) model of scenes and frames is implemented "to explain the experiential basis of text analysis and production in translation" (Risku 2000). Among other approaches, their approach is premised "on the assumption that the world knowledge gained through individual experience plays a dominant role in thinking, understanding, and learning", drawing heavily on prototype theory ${ }^{6}$. Frame semantics has also been applied by Rojo López (e.g., 2002) in accounting for translation of cultural elements, which are to be understood in the context of use.

Another work that avails itself of cognitive linguistics in explaining translation as conceptual issue is that of Kruger (e.g., 2013). The author distinguishes between frame and domain notions. He notices that in frame semantics, information is indexed by a given lexical item, while in domain model, information is distributed among multiple domains (i.e., domain matrix). He holds that domain matrix provides the context against which texts subject of translation are to be understood. It exerts some sort of contextual pressure in a given discourse. Together with the common ground construal, domain matrix determines which information is foregrounded or the other way round, something which helps in explicitation and implicitation. The point is that domains determine the structure and scope of encyclopedic information by means of "contextual selection" and "contextual modulation" (Cruse 2011: 112-113, cited by Kruger, 2013).

Cognitive approach at large has been adopted by Hejwowski (2004), for instance, as well, but this time as a communicative approach through which he explains the intricacies of translation process as a communicative event. This latter adopts all the cognitive constructs that have made a breakthrough in cognitive circles, including, in addition to the elements mentioned above, Sperber and Wilson's 'relevance theory', Grice's 'maxims', among many other theories, providing a fine-grained analysis to the way various constructs interact in a communicative event that involves the recipient, sender, the text, cultural representations, etc.

\footnotetext{
${ }^{6}$ Such a theory, following Risku (2000), changed our conception of "translation as a subjectindependent recoding of a linguistically transparent meaning".
} 
It should be noted that 'simulation model' has also been employed, for example, by Sickinger (2017). The model has been used by the author in approaching the concept of equivalence. He assumes that a translator is required activate her/his simulation in the representational conceptual system in order to capture the sought equivalents.

\subsubsection{Specialized Translation and Terminology}

Substantiation of cognitive models adequacy is also found in works about Terminology and specialized translation. For example, Temmerman (2000) and Faber (2009) flesh out the mainspring role that cognitive paradigm can play in coming to grips with conceptual structures underlying specialized texts and language in general. Faber makes clear that the translation of specialized language texts requires from translators to "go beyond correspondences at the level of individual terms, and be able to establish inter-linguistic references to entire knowledge structures". Otherwise, they cannot straightforwardly comprehend the textual stretches and create their equivalent in the target language (cf. Faber 2009: 108). She notes that an acceptable understanding of the text transcends linguistic knowledge (ibid: 109) in that "a translator must also be aware of the types of conceptual entities that the text is referring to, the events that they are participating in, and how they are interrelated" (ibid: 120-121). Both Faber and Temmerman handle specialized units of understanding through the lines of inquiry concerned with ICMs, Frame Semantics, and Domains.

The above-mentioned models have also been adequately employed in the field of religious translation by McElhannon (e.g., 2005). This latter discusses a number of conceptual issues (in terms of frames, models, and scenarios) and their translation without deviation from the intended messages. He provides examples from the Bible. He points out the inter-domains projections and mappings that a translator needs to understand. The results he gleans are not much different from those reached by other researchers in the field.

To sum up, large knowledge structures, that is, large understanding units reveal the background knowledge and motivation underlying the existence of linguistic items in a language and the way they are used in discourse. They help us see "what information and values are being left unsaid or effaced in a piece of language" (Gee 2010: 67). Accordingly, it is necessary that translation teaching pedagogy places much importance on the aforementioned structures inhabiting the conceptual system where simulation is at play.

\subsection{Teaching the Concept of Equivalence: Conceptual Equivalence}

Apparently, mechanical replacement is workable when it comes to strategies of omission, addition, syntactic reformulation, etc., linear replacement at the lexicosemantic and compositional levels to achieve the grammatical, lexical and semantic equivalents based on the linguistic or taste of the receptor community. 
However, equivalence at the vertical level should be thought of, in classes, as a conceptual dynamic construction. Indeed, the literature falling within cognitive linguistics as applied in translation study insightfully provides us with conceptual mechanisms that may change our conception of equivalence. For instance, frame semantics induces the conception that a translator is required to look for equivalence of the frames - verbalized in the textual surface structure - as a set of conceptual elements (attributes and values) and dynamic relations. Domains theory is conductive to the notion of equivalence of domains, subdomains, and domain matrices which are all provoked by profiles, while conceptual metaphor brings to the fore insights that what is translated is a set of mapped domain properties. In ICMs, equivalence is taken relative to the versions we have about reality, whereas in simulation model, it is construed to be an output of mental simulation and simulators.

It turns out that the concept of equivalence should be highlighted in classroom as a conceptual subject matter ${ }^{7}$ determined by the frames, domains, scripts and models activated in the mind of a translator by way of simulation, i.e., imaginatively acting upon such large structures of knowledge. Students are in need to be taught how to manipulate a number of framed values and attributes in order to capture the sought equivalence, that is to say, in order to avoid deviation from the frames naturally activated by native speakers (cf. Vannerem and SnellHornby 1986: 191; Snell-Hornby 2005: 197). It seems that teaching translation should extend to teaching scientific and philosophical webs of frames (as part of encyclopedic knowledge) in parallel. As such, students would be able to deal with the problem of activation constraints and competition of wrong candidate frames by virtue of the expansion of their bilingual, conceptual (and neuro-cognitive) system as a network of relations (cf. section 1).

In a sense, deviation from the intended messages, in our account, relates to inadvertent conceptual inaccessibility to the source text frames in memory because of the translator's bi-lingual and bi-conceptual asymmetry. It might also be explained in terms of the possible compliance with the target community's linguistic taste, which influences the decision whether an utterance form is acceptable or not. Furthermore, it might relate to systemic factors of the sort handled by Nida. Deviation can equally be motivated by some cultural or ideological drives vis-a-vis a given community's values system and emotional cognitive models in as much as it might be motivated by some cosmopolitan frames; this is the case when it comes to taboo frames. All these factors may lead to the use of frames at odd with the source text frames and intentions (cf. the subsections 1.2.1 and 1.2.2). In what follows, we investigate a bunch of examples (frames), including butterfly effect, political players, uncertainty, DNA, blotting, 'taqrib', etc., with the aim of showing the workability of cognitive linguistics in translation teaching.

7 Following Sickinger (2017: 216-217) "only a small group of researchers and theoreticians have attempted to redefine equivalence from a cognitive point of view". 


\subsubsection{Butterfly Effect Frame}

In the context of Arab Spring, many translators used the idiomatic recurrent expression النقطة التي افاضت الكأس "the drop that makes the glass flood" in (1) as an equivalent of the terms "butterfly effect, catalyzer, fractal, bifurcation point, etc." in order to attune to the Arabic linguistic taste. Perhaps, the use of the expression might also be explained in terms of lack of the source frame in the conceptual system. With regard to value system, Self-immolation in (2), which is metaphorically taken to be a butterfly effect, was frequently translated into suicide:

(1) The Butterfly effect in the Middle East النقطة الني افاضت الكأس في الثرق الأوسط

(2) Bouaazizi's self-immolation إنتحار البوعزيزي

The two terms (self-immolation حرق الذات and suicide الانتحار) serve as points of access to two distinguishable frames. حرق الذات/اضر ام النار في الذات is the equivalent frame of that adopted in English writing; its core attribute, using Barsalous' terms (1992), is setting fire (on oneself), while its core value is being burnt. Suicide is a frame that alludes to a forbidden action. It may activate a web of other frames including mainly hell, punishment by Allah, etc. We hold that when it comes to cultural elements, the onus is on translators whether to resort to foreignization or domestication strategies, using Venuti's terms (1995). However, in both cases, we posit that access to the conceptual system and making use of simulation upon the two competing frames is required, that is, being conscious about what we translate. A translator is not a machine.

Apart from the frame of suicide, in the cosmopolitan era, characteristic of hybridity, it turns out to be difficult to draw a clear borderline between what is local and what is not regarding a number of conceptual categories and frames in some contexts. As a case in point, human rights, democracy, as well as other frames of sense making are at play in local discourses. This is the case concerning, for example, the frame of single mother child بن الام العازبة, which expresses a cosmopolitan phenomenon. In conservative local context, this frame is automatically transformed into illegal child إين غير شرعي (which may be taken as a cultural) element because neither the linguistic system, nor the cultural system can allow single mother child expression in such context as a cognitive model of right and wrong. The concept of 'cultural element', and thus cultural equivalence, applies to suicide (or words like single mother, or consensual relationship, etc.), at least in conservative local contexts, but it does not apply to the example (1).

Students should be made aware that if they linguistically replace frames of "butterfly effect, catalyzer, fractal, bifurcation point, etc.," in (1) with النقطة التي القشة التي قسمت ظهر البعير or, then the epistemologically-based 
metaphorical potential of the mentioned terms would be lost. To put it another way, the cognitive weight intended in 'complex dynamics' and 'chaos theory' frames (cf. Prigogine and Nicolis 1985), as it were, is totally- informationally- lost in the expression provided by the Arabic linguistic system based on usage frequency and linguistic taste. Indeed, both SL expression 'butterfly effect' and TL expression 'the drop that makes the glass flood' seem to represent the image schema of CAUSE and EFFECT. However, it is obvious that the Arabic expression activates different (metaphorical) domain properties. The butterfly effect is a conceptual metaphor whose source domain is chaos theory; it depicts complexity and non-equilibrium which are characteristic of sensitivity to initial conditions, as conceived of in chaos theory, while "the drop that makes the glass flood' may not facilitate access to the said domain, which reflects a scientific connotation. That is, in (1) a scientific source domain in ST is replaced with a general one in TT.

In my point of view, scientific metaphors (used in various discourses) should be kept intact. So, an activation of relevant semantic and conceptual network of frames and domains is prerequisite. In case a student could not activate the conceptual network of 'Complex Dynamics Paradigm' that has replaced the 'Newtonian Paradigm', then it means that he or she needs to establish it in the form of a neuro-conceptual network.

\subsubsection{Political Players Frame}

A similar case of replacement, which is motivated by linguistic taste, or because of inaccessibility, is that of game theory where 'interactional frames' are employed. For example, the constructions used by translators as equivalents for political players (اللاعبون السياسيون) are as follows:

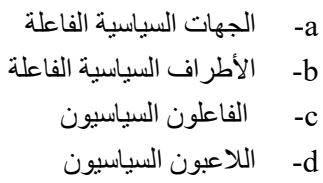

For instance, in the example (3) taken from a United Nations' discourse, الجهات اللاعبون السياسيون (political agents) is used by the translator instead of الفاعلة السياسية (political players):

(3) The European Union calls on all political players to engage constructively in the posttransition process ( $\mathrm{SC} / 8936)$.

ويدعو الاتحاد الأوروبي جميع الجهات الفاعلة السياسية إلى الانخر اط في العمل بشكل بناء في عملية ما بعد الفترة الانتقالية

To the best of my knowledge, game theory-based cognitive model is supposedly used in modelling geopolitics, economy, communication, etc. Hence, it is normal that game theory frames are adopted in various discourses. Game theory is "the 
formal study of conflict and cooperation", and a game is defined in as a "description of a strategic interactive situation" (Turocy 2001). In order to achieve accuracy when translating such a collocation in (3), students should learn to activate the game theory frame or domain used in modelling political situations characteristic of conflict; that is to say, they are required to activate the conceptual metaphor in which game is taken as a source domain of experience. Seemingly, all candidates that compete for activation in the conceptual system share the attribute of "agents" and the value "engagement in politics; however, اللاعبون

metaphorically precise the attribute and value (players - playing the political game). Hence, the analogical mapping established between the game domain and politics domain should be kept intact. What is said about 'political players' applies to other relating conceptual elements (i.e., sub-frames of game frame) like gamers, game changer, cooperative player, non-cooperative player, payoff, etc., which represent conceptual sub-frames of game theory. Indeed, we all have the idealized cognitive model of game; however, the model is not used metaphorically in an Arabic environment, except in few cases; it is thus avoided due to linguistic taste, which is based on frequency.

\subsubsection{Uncertainty Frame}

The concept of uncertainty in (4) is translated into instability or other alternative lexical items because translators are trained to replace items building on linguistic taste. If you take a look at dictionaries (like Almaany, Glosbe, etc.) that provide terms in what is taken to be context, you will find that all the terms below might be employed as equivalents for uncertainty, in physics, politics, and economy, etc.:

Uncertainty
Skepticism, doubt
Indeterminism
Quandary
Instability
Vagueness
Probability

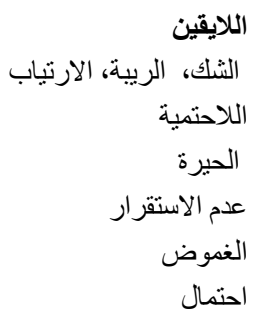

The term 'uncertainty' may provide access to several inter-related frames that show differences in several attributes and values, albeit they may probably share an image schema/attribute of the sort of 'unclearness', we assume. However, it is conceptually clear-cut that instability (or the other terms) cannot play the conceptual role of uncertainty frame as in the following sentence that shows up in a United Nations' discourse:

(4) These efforts remain more urgent given the political uncertainty in Lebanon and the continuing effects of the Syrian crisis. 
النسورية. هذه الجهود ما زال يتسم بأهمية أكثر إلحاحا بالنظر إلى حال عدم الاستقرار السياسي في لبنان واستمرار آثار الأزمة

The conceptual frame as used in Quantum mechanics, by Heisenberg for example, is lost when relegating translation to replacement depending on linguistic taste (i.e., acceptability of forms by community) and frequency, or due to the conceptual inaccessibility to the frame in question. Indeed, uncertainty principle involves a situation with unknown probabilities. Worth noting is that Uncertainty as such has become a central concept in the postmodern rhetoric characterizing our era. As a result, nowadays, we talk about uncertainty in various aspects of life. Seemingly, اللايقين is the most accurate equivalent referent considering this frame's attributes, including probability and unpredictability. الثُك (doubt/skepticism) in our point of view is a mental activity seeking certainty, whereas اللاحتمية (indeterminism) evokes a frame which refers to elements or behaviors that do not determine each other, and so on. Uncertainty principle per se is translated into مبدأ الثكك: thus, Arab students hear or read مبدأ الثنك in both philosophy (Cartesian skepticism) and physics (Heisenberg's uncertainty). So, they may unwillingly activate the same frame for two different frames, otherwise one frame may disturb the representation of the other in the conceptual system.

The examples above reflect the sort of competence (linguistic competence) that translators are trained to put into function when translating. In other words, such examples give us an idea of how translators are taught to linguistically or even culturally replace a lexical unit with an equivalent as merely a linguistic or semantic matter, i.e., translation of form and/or meaning. However, teaching translation process as a linguistic problem solving skill is infelicitous when access to the conceptual system is a requirement.

\subsubsection{Biological Frames: DNA and Blotting...}

Let's take two further examples illustrating our assumption that linguistic replacement is not the whole story in translation process, and, therefore, it should be taken in tandem with conceptualization. The examples are two extracts- taken from texts- provided by Temmerman $(2000,89)$ in the context of Terminology and Specialized Translation (this time the translation is mine). A good translation of the extracts below necessarily entails the activation of cognitive models and frames developed by biologists to capture biological entities and their functions. The configuration of the frame indexed by "nonsense DNA" can more or less be accessed through other terms like "junk DNA", "silent DNA", "intragenic region", "non-informational DNA", "split genes", "genes having an intron-exon structure", "genes in pieces", "intervening sequences", "intragenic regions", "intervening sequence", "internal stretch", etc., given that each term probably facilitates access to values and attributes at variance. In replacement method, nonsense (in nonsense DNA) might wrongly be replaced by many candidate items, including كلام فارغ، سخافة، لغو، بلا معنى، سخيف, ,الهر اء, etc., which are found in 
dictionaries or the mental lexicon of a translator. To choose the exact equivalent referent, one should be familiar with the metaphorical, linguistic cognitive models which are used in micro-biology:

SL

The sequences of nonsense DNA that interrupt genes could be far more important to the evolution of genomes than previously thought, according to researchers. Their study of the model organism Daphnia pulex (water flea) is the first to demonstrate the colonization of a single lineage by "introns," as the interrupting sequences are known that generally direct polypeptide synthesis — are referred to as exons (Berg \& Singer 1992: 126).

TL

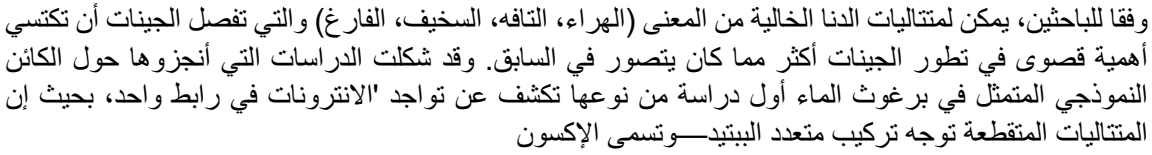

In the conceptual metaphor of "nonsense DNA" in (5), the source domain of experience is language, while the target domain onto which linguistic properties لا يحمل أي معنى، خال من المعنى، بدون معنى (without meaning). In other compilations about DNA, further metaphorical cognitive models are employed in lexicalizing the concept, including, for example, the cybernetic model (non-informational DNA). The same applies to the verb 'interrupt يفصل/يقطع:; in a sentence in linguistic jargon, nonsense words interrupt the continuity of meaning, as it were. Besides, if students are taught about the interacting frames representing DNA concept, then they will readily detect whether exons in "are referred to as exons" refer to "single lineage, or introns, or interrupting sequences, etc.

In order to provide a good rendering for (5), it is not sufficient to replace signs with others based on dictionary, or acceptability of expressions in terms of taste. Instead, the translator is required to be familiar with frames and models used by scientists in molecular biology. Following this line of reasoning, we posit that stretching students' conceptual system into new areas that have some relevance for them is a precondition in order to familiarize thems with the background motivations behind lexical items' functioning. For example, 'nonsense DNA sequences' are to be understood as 'DNA without semantics', or information, or atlas, which serve as metaphorical models used by specialists and experts to capture processes and structures. Furthermore, without background knowledge, translators may find it somehow difficult even to figure out some grammatical patterns, including for example, anaphoric reference as in "are referred to as exons" in (5).

Now let's take a look at the second example in (6): 
(6)

SL

Following ELECTROPHORESIS: the transfer of nucleic acids and/or proteins from a gel strip to a specialized, chemically reactive paper (or other matrix) on which the nucleic acids, etc., may become covalently bound in a pattern similar to that present in the original gel. Transfer may be effected by capillary action - in which case paper [...] is sandwiched between the gel and a highly absorptive pad; alternatively, in electro-blotting, transfer is effected by electrophoresis. In the earliest (capillary) blotting, DNA was transferred to nitrocellulose (in the so-called 'Southern blot' or SOUTHERN HYBRIDIZATION procedure) ...

TL

...نقل الاحماض النووية والبروتينات من شريط هلامي إلى ورق (أو نسيج آخر ) متخصص يتسم بالتفاعل الكيميائي،

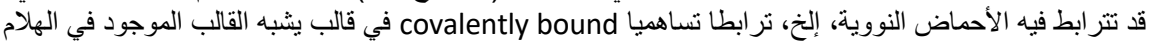

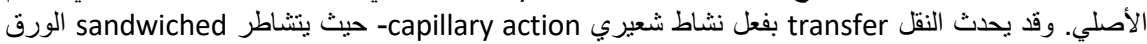
المغلف case paper هلام ولوحة ذات طابع امتصاصي محض. أو الو بدلا من ذللك، فإن النقل في التنشيف الكهربائي

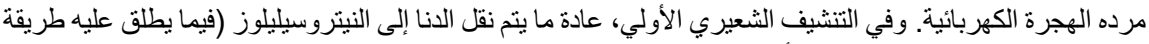
التنشيف الجنوبي Southern blot أو اجراء التهجين الجنوبي) ...

In order to render the lexical items and chunks of the text in (6) in a precise rather than cut and paste fashion, accessibility to the generic frame and secondary frames organizing the whole process (script) of transfer, as well as the involved entities and scenarios, is a precondition. students should be taught that every word in the text, be it content or functional word, can be understood only relative to the whole frame. For example, for activating the right equivalent of the conjuncture 'alternatively' among the possible candidates (تبادليا، تعاقبيا، بدلا من ذلك) it is crucial to activate all the conceptual elements and correlational relations of the whole frame. Likewise, unless the whole frame is accessed, novice translators might encounter some difficulty in reaching the exact equivalents to the following referents: a gel strip, covalently bound, capillary action, original gel, case paper, sandwiched, absorptive pad, electro-blotting, southern blotting, etc. For example, without background knowledge, they may not be sure whether the equivalence of the frame indexed by Pad is وسادة on oو the Pad attributes (like shape and structure) and values (such as functions). The same applies to the frame accessed by 'southern blotting; there are several competing linguistic patterns that might be used as equivalents found in the corpus about micro-biology. However, one should be certain about the exact frame in order to choose the exact pattern:

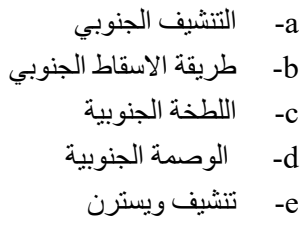


Another point to be made is that the text achieves its coherence and situates itself in a given specialized context through the use of what seems to be conceptual frames (every word or linguistic pattern relates to a frame), image schemas (like TRANSFER/MOVEMENT schema, CAUSE and EFFEC (effected by), SIMILARITY, ACTION, REACTION, etc.) and conceptual metaphors (e.g., Reactive paper, absorptive pad), SCRIPT (sequences of mico-events), among other things.

\subsubsection{Taqrib (reducing distance) Frame}

Now, consider the translation of the last example 'taqrib' in (7) as used by Arab traditional scholars. The signification of the term 'taqrib' is polysemous; it differs according to the field and context of use. Note that dictionaries would not provide the equivalence of the various concepts associated with the symbolic vehicle 'taqrib'. Teachers are required to teach their translation students how to use the term depending on contextual cues. This sort of form is a prompt (or access point) to a bunch of conceptual structures including the generic frame (reducing distance) and sub-frames etc. One should be aware of the domains distributed in the juxtapositions in sentences (domain matrix), which provide the context of the concept of 'taqrib' and the contextual pressure exerted on it (cf. Kruger, 2013 for details on domain matrix concept in translation).

These are some of the probable sub-frames (sub-domains) that can be accessed by 'taqrib' in (7): approaching frame (a), simplification frame (b), getting closer frame (c), lifting frame (d), abridgement frame (e), conciliation frame (f), evidence frame $(\mathrm{g})$, exactness frame $(\mathrm{h})$. The core sense of the generic frame extends to peripheral ones by means of the sort of radiation mechanism hypothesized by Lakoff (cf. Geeraerts 2009). Each sense is related to the generic category (frame) by virtue of family membership. There is a core attribute, using barsalou's (1992) terms, which is 'reducing distance' among entities (be they concrete or abstract): between a researcher and a subject, a person and reality, a person and another, a person and faith, a person and a place, a subject and a reader, etc. Alternatively, with reference to image schema as suggested by Lakoff (1987), Lakoff and Turner (1989) and Johnson (1987), we may say that "reducing distance" is an image schema that extends into a number of domains. The use or identification of each domain (frame) is constrained by Context which exerts pressure on properties, values and conceptual correlations in as much as constraining neuro-cognitive circuitry. We mean by context the internal textual environment (i.e., linguistic juxtaposition) and the external extra knowledge (the translation is mine):

SL

a - الثقريب عملية تداولية يسعى من خلالها المقرّب إلى صياغة خطاب علمي، يستوعب المضامين البعيدة والقريبة 


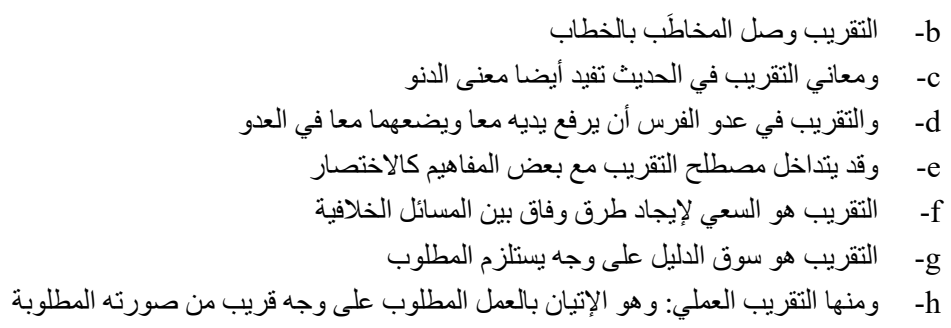

TL

a- Taqrib is a pragmatic process through which the agent who practices taqrib (Almoqarib) tries to draw up a scientific discourse... (approaching frame)

b- Taqrib is to get a given discourse across to the addressee... (simplification frame)

c- Taqrib meanings in Hadith refer to getting closer... (getting closer frame)

d- Taqrib in a horse gallop means that it lifts its two front legs and put them in the gallop... (lifting the front legs frame)

e- Taqrib term may overlap with concepts as abridgement... (abridgement frame)

f- Taqrib is the quest to find out ways of reconciling the controversial issues... (conciliation frame)

g- Taqrib is to provide evidence (giving evidence frame)

h- Taqrib in practice: performing the required task in exactly as it is perceived to be done... (exactness frame)

For providing the required equivalent of 'Tqarib' in each instance, students need to get access to the exact frame that allows the configuration of the term; that is, conceptualization first, then comes the linguistic form. They are required to activate the whole frame of 'taqrib' and its constituting frames in Arabic.

In a nutshell, translation students may need to refine their conceptual competence for translation purpose in order to be able to insure a good quality translation, which requires from them not only comprehension of the source language, but also the prerequisite activation of extra-linguistic knowledge together with situational knowledge (Hartmann 1990; Wilss 1990). The linguistic semantic elements in a text to be translated serve as external stimuli to activate knowledge in our memory (Wilss,1990: 19, cited by Kwon et al 2009, 110), i.e., knowledge structured in frames, domains, scripts, cognitive models, etc., as the examples dealt with. Building on the lines of argumentation throughout the sections of the paper, it seems that mechanical replacement of linguistic items with their supposed equivalent items (i.e., substitutability of words) does not work when access to the conceptual system is requisite. Hence, it is worthwhile explaining the frames used in the discourses dealt with in classroom before proceeding with linguistic replacement. Through such a frequent exercise, students would cognitively establish a model of how to approach textual, schemas, frames and domains. 


\section{General conclusion}

Our lines of argumentation for the importance of cognitive linguistics modelling in translation and translation teaching and pedagogy reveal that conceptual competence is prerequisite for being a qualified translator who can conceptualize equivalence in an accurate manner. Thus, translation students' qualifications should be measured in terms of the systematic use of their conceptual system rather than just their manipulation degree of the linguistic network nodes. Because of having a good or excellent command of the linguistic system, translation students may perform well at the horizontal, syntagmatic levels (lexical, grammatical, compositional); however, their translation might be characteristic of conceptual entropic behavior at the level of some given lexico-semantic nodes that entail the activation of relevant conceptual webs of knowledge frames.

The theoretical constructs laid out in the paper are of vital importance in informing our understanding of the conceptual system structures involved in the search for equivalence. Through the examples on which we have applied such theoretical devices, albeit under the umbrella term 'frame' in many cases, it turns out to be clear-cut that a translator may need to develop his /her academic conceptual system through acquiring new frames, expanding others, and being familiar with how to use the existing ones in the conceptual system. In this connection, teachers are required to teach the frames organizing knowledge in philosophy, science, politics, economy, and culture at large, etc., that is, knowledge conceptual network. More to the point, it turns out to be requisite to teach students other conceptual mechanisms, including simulation, that would enable them to trace concepts back to their source domains in the theoretical models used in other scientific or humanist fields, or even those relating to sense making. After the reconnaissance period, rhetoric and discourse at large have become schematically replete with modern conceptual metaphors and frames belonging to the modern reasoning in various knowledge paradigms. Thus, conceptual metaphor plays a major role in expressing various frames and domains of experiences and in the knowledge architecture. A plethora of structures, properties and values have been mapped onto discursive patterns.

Translation of specialized texts, like those belonging to microbiology we dealt with as an example of scientific translation, requires accessibility to the intended frames, schemas, models and domains, etc. In order for students to straightforwardly render texts, it is prerequisite for them to have some specific background representations in their mental spaces, that is to say, the conceptualization underlying the source and target signs. Without a wellestablished background, or at least techniques of scientific research, translators may be in a state of uncertainty in terms of decision making concerning many cases, something which might motivate the activation of wrong candidates. Note that context, as a conceptual construct, is crucial in selecting the exact lexico- 
semantic units or linguistic patterns; contextual clues help activate the concerned frames.

Translation is not always horizontal; that is, translation is not just a matter of replacing items depending on linguistic taste and acceptability of linguistic patterns or frames in the target linguistic or cultural systems. In traditional, pedagogical translation methods, students are given texts, and they are asked to provide the equivalence of items, using dictionary, and resting on linguistic taste and frequency of usage. This kind of replacement is useful in all the cases that do not require conceptualization; for example, a 'car is a car'. However, some nodes require the activation of frames and webs of relations held among attributes and values, which might dynamically propagate or be reduced depending on contextual constraints.

In traditional methods, students need to memorize lists of terms, words and collocations in order to reuse them in exams, while they may lack the conceptual representations to which those items are supposed to facilitate access. If a linguistic item is cognitively taken together with the conceptual frame (or domain or model) to which it belongs, activation would be readily operationalized and more accurate. In cognitive linguistics, conceptual elements are taken to coactivate each other within webs of various types of relations (part-whole, is-kindof, enablement, containment, etc.), and this is called spread of activation.

To sum up, translation is more than merely coming to grips with the juxtaposed lexico-semantic units and their transfer depending on the linguistic system knowledge. Rather, it is to be taken as a dynamic process of rendering a range of extra-linguistic, perceptual and conceptual structures (i.e., conceptual/cognitive equivalence). The point is that linguistic units configured in the textual surface level should function to serve as nodes via which translators, by means of perceptual simulation, activate a vast conceptual network that is supposed to exist in the conceptual system of a translator in the form of frames, cognitive models, domains, schemas, and cross-domain mappings, etc.

\section{References}

Barsalou, Lawrence W. 1992. Frames, Concepts, and Conceptual Fields. In Lehrer, A. \& Kittay, E.F. (eds.), Frames, Fields, and Contrasts, Lawrence Erlbaum Associates Publishers. 21-74.

Barsalou, Lawrence, W. 2003b. Situated simulation in the human conceptual system. Language \& Cognitive Processes, 18, 513-562.

Brislin, Richard, W. 1970. Back-Translation for Cross-Cultural Research. Journal of Cross-Cultural Psychology 1. 185-216.

Bybee, Joan. 2003. Mechanisms of Change in Grammaticization: The Role of Frequency. In B. Joseph and R. Janda (eds.), The Handbook of Historical Linguistics; 602-623. Oxford: Blackwell.

Cienki, Alan. 2010. Frames, Idealized Cognitive Models, and Domains. The Oxford Handbook of Cognitive Linguistics Edited by Dirk Geeraerts and Hubert Cuyckens. 
Christoffels, Ingrid K and De Groot, Annette M.B. 2005. Simultaneous interpreting: A cognitive perspective. In J. Kroll and A. M. B. de Groot (eds.), Handbook of bilingualism: Psycholinguistic approaches. 454-479. New York: Oxford University Press.

Clausner, Timothy C, Croft, William. 1999. Cognitive Linguistics 10 (1). 1-31.

Coulson, Seana and Teenie, Matlock. 2009. Cognitive science. In S. Dominiek, J. O. Östman and J. Verschueren, Cognition and Pragmatics (ed.), 86-109.

Cronin, Michael. 2006. Translation and Identity. Abingdon/New York: Routledge.

Cruse, Alan. 2011. Meaning in Language: An Introduction to Semantics and Pragmatics. Oxford University Press UK

De Groot, Annette M.B. 2011. Language and Cognition in Bilinguals and Multilinguals: An Introduction. New York and Hove: Psychology Press.

Ellis, Nick C. et al 2008. Formulaic Language in Native and. Second Language Speakers: Psycholinguistics, Corpus Linguistics, and TESOL.TESOL QUARTERLY, 42(3).

Evans, Vyvyan et al. 2007. The Cognitive linguistics enterprise: an overview. In V Evans, B Bergen and J Zinken (eds.), The cognitive linguistics reader. Advances in cognitive linguistics, Equinox Publishing Ltd, London, 2-36.

Evans. Vyvyan. 2009. How Words Mean: Lexical Concepts, Cognitive Models, and Meaning Construction. Oxford University Press.

Faber, Pamela B. 2009. The cognitive shift in terminology and specialized translation. Monografías de Traducción e Interpretación, MonTI. 1. 10.6035/MonTI.2009.1.5.

Fauconnier, Gilles, Turner, Mark. 2002. The way we think: Conceptual blending and the mind's hidden complexities. Basic Books.

Feldman, Jerome, A. 2006. From Molecule to Metaphor: A Neural theory of Language. MIT Press.

Fillmore, Charles J. 1977a. Scenes-and-frames semantics. In Linguistics Structures Processing, ed. by Antonio ZampolliAmsterdam and New York: North Holland Publishing Company? 55-81.

Fillmore, Charles. 1985. Frames and the Semantics of Understanding. Quaderni di Semantica, 6, 222-254.

Gee, James P. 2010. An introduction to discourse analysis: Theory and method. Taylor \& Francis

Geeraerts, Dirk. 2009. Theories of Lexical Semantics. Oxford University Press. Clara Molina, Universidad Autónoma.

Grice, Paul. 1989. Studies in the Way of Words. Cambridge Massachusetts: Harvard University Press.

Halverson, Sandra L. 2014. Reorienting Translation Studies: Cognitive Approaches and the Centrality of the Translator. In: J. House (ed.), Translation: A Multidisciplinary Approach.Palgrave Advances in Language and Linguistics. Palgrave.

Hejwowski, Krzysztof. 2004. Translation: a cognitive-communicative approach. Olecko: Wydawnictwo Wszechnicy Mazurskiej,

Holmes, Games S. 1988. Translated Papers on Literary Translation and Translation Studies. Rodopi, Amsterdam.

Kiraly, Donald C. 1995. Pathways to Translation: Pedagogy and Process. Kent State University Press.

Kitis. Eliza. 2009. The pragmatic infrastructure of translation. Traduçãoe Comunicação. Revista Brasileira de Tradutores 18.

Königs, Frank. G. 1987. Was beim Übersetzen passiert; Theoretische Aspekte, empirische Befunde und praktische Konsequenzen. Die neueren Sprachen, 2, 162-185.

Krüger, Ralph. 2013. A Cognitive Linguistic Perspective on Explicitation and Implicitation in Scientific and Technical Translation. trans-kom, Vol. 6, 285-314

Kwon, Hazel, K., et al. 2009. Assessing cultural differences in translations : A semantic network analysis of the universal declaration of human rights. Journal of International and Intercultural Communication, 2(2). 107-138. 
Lakoff, George. 1987. Women, Fire and Dangerous Things: What Categories Reveal about the Mind. Chicago: The University of Chicago Press.

Lakoff, George. 1993. In A. Ortony (ed.), Metaphor and Thought, 202-251. Cambridge University Press.

Lakoff, George. 1996. Moral Politics: What Conservatives Know That Liberals Don't. Chicago: University of Chicago Press

Lakoff, George., \& Turner, Mark. 1989. More Than Cool Reason: A Field Guide to Poetic Metaphor. Chicago: University of Chicago Press.

Johnson, Mark. 1987. The body in the mind: The bodily basis of meaning, imagination, and reason. University of Chicago Press.

Johnson-Laird, Philip N. 1983. Mental Models. Towards a Cognitive Science of Language, Inference and Consciousness. Cambridge, UK: Cambridge University Press

Langacker, Ronald. W. 1986. An introduction to cognitive grammar. Cognitive Science, 10, 1-40.

Langacker, Ronald. W. 1987. Foundations of Cognitive Grammar. Vol. I: Theoretical Prerequisites. Stanford, CA: Stanford University Press.

Langacker, Ronald. W. 2000. A dynamic usage-based model. In: Michael Barlow \& Suzanne Kemmer (eds.) Usage-Based Models of Language. Stanford: CSLI, 1-63.

Langacker, Ronald. W. 2008. Cognitive Grammar: A Basic Introduction. Oxford University Press.

MacWhinney, Brian. 1997 Second language acquisition and the competition model. In De Groot, A.

M. B., and Kroll, J. F. (eds.), Tutorials in bilingualism: psycholinguistic perspectives, 113-142.

Rojo López, Ana M. (2002). Applying Frame Semantics to Translation: A Practical Example. Meta, 47(3), 312-350. https://doi.org/10.7202/008018ar

McClelland, James L. 2013a. Integrating probabilistic models of perception and interactive neural networks: A historical and tutorial review. Frontiers in Psychology.

McElhanon, Kenneth A. 2005. From word to scenario: the influence of linguistic theories upon models of translation. Journal of Translation, 1(3), 29-67.

Nida, Eugene A. 1975b. Exploring semantic structures. Munich: Wilhelm Fink.

Paradis, Michel. 1994. Neurolinguistic aspects of implicit and explicit memory: implications for bilingualism. In N. Ellis (ed.), Implicit and explicit learning of Second Languages. 393-419. London: Academic Press.

Prigogine Ilya, Nicolis, Gregoire. 1985. Self-Organisation in Nonequilibrium Systems: Towards A Dynamics of Complexity. In: Hazewinkel M., Jurkovich R., Paelinck J.H.P. (eds) Bifurcation Analysis. Springer, Dordrecht. https://doi.org/10.1007/978-94-009-6239-2_1

Risku, H. 2010. A cognitive scientific view on technical communication and translation: Do embodiment and situatedness really make a difference?" Target 22 (1). 94-111.

Risku, $\mathrm{H}$ et al. 2013. A dynamic network model of translatorial cognition and action. Translation Spaces, 2, 151-182.

Rojo López, A. 2002. Applying Frame Semantics to Translation: A Practical Example. Meta, 47(3), 312-350. https://doi.org/10.7202/008018ar.

Sickinger. Pawel. 2017. Aiming for Cognitive Equivalence - Mental Models as a Tertium Comparationis for Translation and Empirical Semantics. Research in Language, 15(2). 213-236.

Shannon, Claud. E. 1948. A Mathematical Theory of Communication. Bell System Technical Journal, 27(3).

Snell-Hornby, Mary. 2005. Of catfish and blue bananas: scenes-and-frames semantics as a contrastive 'knowledge system' for translation.' In: DAM, V.; ENGBERG, J.; GERZYMISCHARGBOGAST, H. (eds.) Knowledge systems and translation. Berlin/New York: Mouton de Gruyter. 193-206

Temmerman, Rita. 2000. Towards New Ways of Terminology Description. The SociocognitiveApproach, Amsterdam/Philadelphia, Amsterdam: John Benjamins Publishing Company.

Termina, Baaziz. 2018. Semantic Uncertainty and Cognitive Noise. مجلة أبحاث لسانية11. 009-034-000-1360/10.37257. 
Toury, Gideon. 1995. Descriptive Translation Studies and Beyond. John Benjamins Publishing.

Turocy, Theodore L. and Bernhard von Stengel. 2001. Game Theory. CDAM Research Report LSECDAM- 2001-09.

Vannerem, Mia and Snell-Hornby, Mary.1986. Die Szene hinter dem Text: 'Scenes-and-frames semantics' in der Übersetzung. In M. Snell-Hornby (ed.), Übersetzungswissenschaft: eine Neuorientierung. Zur Integrierung von Theorie und Praxis, 184-205. Vienna: WUVUniversitätsverlag.

Venuti, Lawrence. 1995. The Translator's Invisibility: A History of Translation. London; New York: Routledge.

Zwaan, R. 2004. Moving words: Dynamic representations in language comprehension. Cognitive Science, 28, 611-619. 